\title{
A Comparison on illustration of story and narration of illustration
}

\author{
Selma Korkmaz ${ }^{1, *}$ \\ ${ }^{1}$ Near East University, Ataturk Faculty of Education, Department of Turkish Language Teaching, \\ 99138 Nicosia, North Cyprus
}

\begin{abstract}
The purpose of Turkish classes is to equip students with the ability of comprehension and narration. Everyone knows that stories covered in Turkish courses are offered with visuals, meaning pictures, so that they could be more easily understood. Illustration of a read story and narration of a picture shown can help explore the extent to which the topic is comprehended and how it is narrated, meaning visual presentation and visual reading skills. The purpose of this study is to compare whether attention is paid to several elements such as event, time, place, persons, language and narration/visual language during the illustration of a story and narration of a picture shown, meaning whether a connection is established between the narrated story and drawn picture as well as between the shown picture and the narrated story. Study group consists of 35 pre-service teachers who are junior students at Turkish language teaching department of Atatürk Education Faculty at Near East University. Document analysis, which is a qualitative research method, was employed and several stories and pictures were used as data collection tools. Descriptive analysis, percentage and frequency were used in the analysis of data. Based on the obtained findings, we can claim that pre-service teachers are more skilled in narration of picture compared to illustration of stories, meaning that their visual reading skills are superior to their visual presentation skills.
\end{abstract}

\section{Introduction}

The purpose of Turkish courses is to equip students with the skill of understanding and narrating what they see, watch, listen and read. Visuals have a special place in the development of understanding and narrating skills. Everyone knows that stories covered in Turkish courses are offered with visuals, meaning pictures, so that they could be more easily understood. The purpose here is to facilitate the receipt of knowledge in the text, concretize the knowledge that is to be conveyed, display the knowledge in its entirety, ensure that the knowledge is easily recalled, facilitate the understandings of the knowledge, motivating the individual, attract attention and increase attractiveness. Ausburn claimed that visual thinking and learning improved narration skills, increased the interest and

*Corresponding author: selma.korkmaz@neu.edu.tr 
motivation of students, contributed to the organization of opinions and self-expression, helped independent thinking and, most importantly, facilitated learning [1].

Pictures are among the first elements that come to mind when the word "visual" is mentioned. The major functions of pictures are emphasizing differences, establishing analogy relations, bringing attention to the forefront and ensuring that some elements are remembered. At this point, whether the preferred pictures are convenient for the topic and the purpose bears huge importance [2]. Başaran stated that concrete and abstract concepts could be described easily using pictures and the subject could be explained better and in a shorter period of time through visuals [3].

One can explore how a subject is understood and narrated through illustration of a read story and narration of a shown picture, which indicate visual presentation and reading skills. The purpose of this study is to compare whether attention is paid to several elements such as event, time, place, persons, language and narration/visual language during the illustration of a story and narration of a picture shown, meaning whether a connection is established between the narrated story and drawn picture as well as between the shown picture and the narrated story.

\section{Method}

\subsection{Study Group}

Our study group consists of 35 pre-service teachers who are junior students at Turkish language teaching department of Atatürk Education Faculty at Near East University. As the courses related to the four basic language skills are completed in the $3^{\text {rd }}$ grade, it is believed that conducting this study with pre-service teachers studying at $3^{\text {rd }}$ grade of Turkish language teaching department would be meaningful.

\subsection{Collection of Data}

During the collection of data, document analysis was employed which is a qualitative research method; as a result, several pictures and stories were used as data collection tools.

\subsection{Analysis and Interpretation of Data}

Descriptive analysis, percentage and frequency were used in the analysis of data. The opinions of two Turkish language experts and two drawing experts were consulted in the analysis of data.

\section{Findings and Comments}

\subsection{Findings concerning the story line during the illustration of a read story and narration of a shown picture}

Table 1. Frequency and percentage distribution of pre-service teachers concerning the story line during the illustration of a read story and narration of a shown picture

\begin{tabular}{lcc}
\hline Group & f & $\mathbf{\%}$ \\
\hline Illustration of story & 18 & 51,42 \\
Narration of picture & 32 & 91,42 \\
\hline
\end{tabular}


An examination of table 1 shows that $51.42 \%$ of pre-service teachers conveyed the story line properly while illustrating the story whereas $91.42 \%$ conveyed the story line properly while narrating the picture.

In the story about two camping friends helping a person who was attacked by a bear, it is observed that most pre-service teachers drew people having fun in the camp.

In the picture, it is explained that children who go out to the street and park as the spring comes played ball and marbles, rode bicycles and people chatted at the park. However, it is observed that a few pre-service teachers misinterpreted the picture while telling the story line and mentioned the people who left the neighborhood and sad children.

\subsection{Findings concerning the time during the illustration of a read story and narration of a shown picture}

Table 2. Frequency and percentage distribution of pre-service teachers concerning the time during the illustration of a read story and narration of a shown picture

\begin{tabular}{lcc}
\hline Group & f & $\mathbf{\%}$ \\
\hline Illustration of story & 17 & 48,57 \\
Narration of picture & 29 & 82,85 \\
\hline
\end{tabular}

An examination of table 2 shows that $48.57 \%$ of pre-service teachers conveyed the time properly while illustrating the story whereas $82.85 \%$ conveyed the time properly while narrating the picture.

Both the story and the picture mentions spring season but while narrating the story it is stated that there is still snow in the mountain although it is spring time. However, it is determined that a majority of pre-service teachers were mistaken about the time while illustrating the story whereas some were mistaken while narrating the picture; some even did not mention time at all. It is revealed that pre-service teachers mentioned time using such expressions as spring season, month of May while narrating the picture.

\subsection{Findings concerning the place during the illustration of a read story and narration of a shown picture}

Table 3. Frequency and percentage distribution of pre-service teachers concerning the place during the illustration of a read story and narration of a shown picture

\begin{tabular}{lcc}
\hline Group & f & $\mathbf{\%}$ \\
\hline Illustration of story & 32 & 91,42 \\
Narration of picture & 33 & 94,28 \\
\hline
\end{tabular}

An examination of table 3 shows that $91.42 \%$ of pre-service teachers conveyed the place properly while illustrating the story whereas $94.28 \%$ conveyed the place properly while narrating the picture.

The story mentions a mountainous area. The picture is about a park, street or neighborhood in a village or town. It is explored that very few teacher candidates did not draw a mountainous region while illustrating the story and mention the place while narrating the picture. 


\subsection{Findings concerning the people during the illustration of a read story and narration of a shown picture}

Table 4. Frequency and percentage distribution of pre-service teachers concerning the people during the illustration of a read story and narration of a shown picture

\begin{tabular}{lcc}
\hline Group & f & \% \\
\hline Illustration of story & 27 & 77,14 \\
Narration of picture & 34 & 97,14 \\
\hline
\end{tabular}

In table 4 , it is seen that $77.14 \%$ of pre-service teachers conveyed the people properly while illustrating the story whereas $97.14 \%$ conveyed the people properly while narrating the picture.

It is seen that there are three people in the story and several children and people in the picture. It is observed that while illustrating the story several pre-service teachers omitted some people whereas only one pre-service teacher did not mention people while narrating the picture.

\subsection{Findings concerning the language and narration/visual language during the illustration of a read story and narration of a shown picture}

Table 5. Frequency and percentage distribution of pre-service teachers concerning the language and narration/visual language during the illustration of a read story and narration of a shown picture

\begin{tabular}{lcc}
\hline Group & f & $\mathbf{\%}$ \\
\hline Illustration of story & 23 & 65,71 \\
Narration of picture & 33 & 94,28 \\
\hline
\end{tabular}

An examination of table 5 shows that $65.71 \%$ of pre-service teachers used visual language properly while illustrating the story and described some materials used during camping and that $94.28 \%$ paid attention to using a plain and fluent language while illustrating the picture; they also made wide use of descriptions.

\section{Discussion, Conclusion and Recommendations}

Based on the obtained findings, it has been found out that pre-service teachers are more skilled in narration of picture compared to illustration of stories, meaning that their visual reading skills are superior to their visual presentation skills.

Despite the fact that spring time is mentioned both in the story and in the picture, as the venue of the event told in the picture is mountainous regions, it is told that there is still snow all around. However, an examination of the documents of pre-service teachers shows that they gave more accurate descriptions of the time in stories whereas many people misperceived the time in the pictures they drew.

It became clear that a majority of pre-service teachers conveyed the place accurately in the stories they told and the pictures they drew.

It has been found out that while pre-service teachers illustrated the story, they omitted some people but while they narrated the picture, they mentioned all the people in the picture.

It can be claimed that the language and narration used by pre-service teachers while narrating the picture is very good and they made better use of descriptions whereas while they illustrated stories their visual language was not that good as the omitted many descriptions which were included in the story. 
In conclusion, we can claim that visual reading skills of pre-service teachers are much better than their visual presentation skills. It has been found out that pre-service teachers made sense of pictures accurately but many pre-service teachers failed to illustrate a story properly. This, in turn, makes clear that pre-service teachers have good comprehension of the elements in the picture but are unable to understand the elements in the story accurately or did not pay attention to these elements. Above all, pre-service teachers should know what the elements are that they must pay attention in both stories and pictures. Pre-service teachers can be taught how to use these elements and help them establish a meaning between the story and the picture. Köksal et al. stated that if the students are not taught how to use these elements, they cannot make effective sense between the story and the visual [4].

In addition, this result displays the fact that visual elements are more easily remembered but the elements in stories are forgotten more rapidly. It is believed that in order to make better sense of the story line and ensure permanence of the narration, stories should be handled along with visuals. It can be claimed that through visual presentations used during the transfer of knowledge the individual can perform visual reading and comprehend the information better; he/she can also ensure permanence of the information. Begoray displayed that visuals have essential contribution in the comprehension by students of the red or covered subject [5].

This study displays that written language skills of pre-service teachers is better than their visual language skills. Thus, it is possible to see the positive impact of pictures on comprehension and writing skills, which are among basic language skills in Turkish courses. Özbay also claimed that pictures have huge contribution in the development of comprehension and writing skills [6].

Based on this conclusion, it is believed that following the recommendations listed below would be beneficial:

- A course titled "visual reading and visual presentation" can be added to the Turkish language teaching program.

- Visual presentation skills of pre-service teachers can be improved through various activities.

- Panels and conferences can be organized for pre-service teachers and information can be given on visual presentation.

- It can be ensured that pre-service teachers have the awareness that visual presentation is as important as visual reading.

\section{References}

1. F. B. Ausburn, A comparison of multiple and linear image presentations of a comparative visual location task with visual and haptic college students, ERIC (1975).

2. H. Akyol, Turkish teaching methods Kök Publications, Ankara, (2006).

3. M. Başaran, usage of teaching materials of $4^{\text {th }}$ and $5^{\text {th }}$ grade students at Turkish courses. Unpublished MA Thesis, Gazi University. Gazi Graduate School of Education Sciences, Ankara, 21 (2003).

4. K. Köksal, T. Temur, H. Akçam, A study on the visual reading skills of elementary first grade students, National Classroom Teaching Congress, 14-16 April 2006, Gazi University, Ankara (2006).

5. D. Begoray, Through a class darkly: Visual literacy in the classroom, Canadian Journal of Education, 26/2, 201-217 (2001).

6. M. Özbay, Turkish special teaching methods I. Öncü Books, Ankara, (2011). 